\title{
Effects of the Toll-like receptor 7 (TLR7) agonist, AZD8848, on allergen-induced responses in patients with mild asthma: a double-blind, randomised, parallel-group study
}

Brian R. Leaker ${ }^{1 *}$, Dave Singh ${ }^{2}$, Sam Lindgren ${ }^{3}$, Gun Almqvist ${ }^{3}$, Leif Eriksson ${ }^{4}$, Barbara Young ${ }^{5}$ and Brian O'Connor ${ }^{1}$

\begin{abstract}
Background: Although allergic asthma is a complex area with many interacting factors involved, the 'hygiene hypothesis' proposes that a lack of exposure to infection during childhood may polarise the immune system towards allergen-reactive Th2-type responses in genetically susceptible individuals. Toll-like receptors (TLRs) play a key role within the innate immune system and TLR7 agonists have previously been shown to up-regulate Th1 responses and down-regulate Th2 responses to allergens in murine models of allergic or chronic asthma. This study aimed to examine the efficacy and safety of the novel TRL7 agonist AZD8848, which has been developed as an antedrug.

Methods: In this double-blind, randomised, parallel-group study, AZD8848 $60 \mu \mathrm{g}$ or placebo was administered intranasally once-weekly for 8 weeks in patients with mild-to-moderate allergic asthma (NCT00999466). Efficacy assessments were performed at 1 and 4 weeks after the last dose. The primary outcome was the late asthmatic response (LAR) fall in forced expiratory volume in $1 \mathrm{~s}\left(\mathrm{FEV}_{1}\right)$ after allergen challenge at 1-week post-treatment.

Results: AZD8848 significantly reduced average LAR fall in $\mathrm{FEV}_{1}$ by $27 \%$ vs. placebo at 1 week after treatment $(p=0.035)$. This effect was sustained at 4 weeks post-treatment; however, it did not reach clinical significance. AZD8848 reduced post-allergen challenge methacholine-induced airway hyper-responsiveness (AHR) vs. placebo at 1 week post-dosing (treatment ratio: 2.20, $p=0.024$ ), with no effect at 4 weeks. There was no significant difference between the two groups in plasma cytokine, sputum Th2 cytokine or eosinophil responses post-allergen challenge at 1 week after treatment. The incidence of adverse events was similar in the two groups. AZD8848 was generally well tolerated.
\end{abstract}

Conclusions and clinical relevance: In patients with allergic asthma, TLR7 agonists could potentially reduce allergen responsiveness by stimulating Type 1 interferon responses to down-regulate the dominant Th2 responses.

Trial registration: clinicaltrials.gov identifier NCT00999466.

Keywords: Allergic asthma, Hygiene hypothesis, Type 1 interferon, Innate immune system

\footnotetext{
*Correspondence: brian.leaker@qasmc.com

${ }^{1}$ Respiratory Clinical Trials Ltd, Queen Anne Street Medical Centre, 18-22

Queen Anne Street, London W1G 8HU, UK

Full list of author information is available at the end of the article
}

(c) The Author(s). 2019 Open Access This article is distributed under the terms of the Creative Commons Attribution 4.0 International License (http://creativecommons.org/licenses/by/4.0/), which permits unrestricted use, distribution, and reproduction in any medium, provided you give appropriate credit to the original author(s) and the source, provide a link to the Creative Commons license, and indicate if changes were made. The Creative Commons Public Domain Dedication waiver (http://creativecommons.org/publicdomain/zero/1.0/) applies to the data made available in this article, unless otherwise stated. 


\section{Background}

The global prevalence of allergic diseases has continued to rise in recent decades, despite some evidence of a trend towards a plateau in asthma prevalence in developed countries [1]. Some epidemiological findings have suggested that this increase may be attributed to a reduced childhood exposure to infection as a result of antibiotics, vaccination and improved sanitation [2, 3]. Thelper (Th) 1, Th2 and $\mathrm{T}$ regulatory $\left(\mathrm{T}_{\text {reg }}\right)$ cells play a vital role in regulating adaptive immune responses to infection [4]. The 'hygiene hypothesis' proposes that a reduction in Th1 or $\mathrm{T}_{\text {reg }}$-like responses resulting from lack of exposure to infection during childhood may polarise the immune system towards allergen-reactive Th2-type responses in genetically susceptible individuals. A recent study reported that an Amish farming community exposed to microbial products and lipopolysaccharide (LPS) demonstrated increased innate immune responses and an associated low overall incidence of asthma and allergy $[5,6]$.

Allergic asthma is a chronic inflammatory disorder of the airways characterised by eosinophil infiltration, airway hyper-responsiveness (AHR) and excessive airway mucus production $[7,8]$. Th2 cells respond to environmental antigens by secreting a range of cytokines, including interleukin (IL)-4, IL-5, IL-9 and IL-13 [7]. Such responses can be suppressed by $\mathrm{T}_{\text {reg }}$ cells through the secretion of the anti-inflammatory cytokine IL-10 [9] and type II interferon gamma (IFNY) secreted by Th1 cells [10].

Toll-like receptors (TLRs) play a key role within the innate immune system by recognising pathogenassociated molecular patterns (PAMPs) via a leucinerich pattern recognition receptor (PRR) domain $[11,12]$. TLR7, primarily expressed by plasmacytoid dendritic cells, detects infection by single-stranded ribonucleic acid (ssRNA) viruses, including influenza, coronavirus and rhinovirus [13]. TLR7 activation triggers an innate immune response, with a signalling cascade involving the recruitment of Myeloid differentiation primary response 88 (MyD88), interleukin-1 receptor-associated kinase 1 (IRAK-1), interleukin-1 receptor-associated kinase 4 (IRAK-4), TNF receptor-associated factor 6 (TRAF6) and interferon regulatory factor 7 (IRF-7) [14]. Phosphorylated IRF-7 subsequently upregulates the production of the type I interferons (IFNs) which help regulate the activity of the immune system.

TLR7 agonists have potential as a new treatment option for allergic asthma by reducing responsiveness to allergens. TLR7 agonists have been shown to upregulate Th1 responses and downregulate Th2 responses to allergens in murine models of allergic or chronic asthma through a variety of complex mechanisms, such as activating nuclear factor NF- $\mathrm{kB}$ pathway transcription factors to increase production of cytokines, including IL-12, chemokines and Type I IFNs such as IFN $\alpha$; some also appear to depend on the type II IFN $\gamma$ [15-18]. AZD8848 is a novel TLR7 agonist being developed for the treatment of asthma and allergic rhinitis. In order to restrict the effects of the drug to the site of administration and to minimise any potential for side effects associated with systemic cytokine production, AZD8848 has been designed as an antedrug. This metabolically labile ester is topically active but is rapidly hydrolysed by butyrylcholinesterase to a much less active metabolite upon entry to the circulation [19].

In this study, AZD8848 was administered intranasally to minimise any risk of local inflammatory effects in the lungs and to further reduce the risk of systemic activity. Early murine studies showed localised inflammatory effects in the lungs at high doses, with partial resolution on cessation and with complete resolution at lower doses. Other studies had demonstrated efficacy with both inhaled and intranasal administration and so, supported by other evidence for an immunological linkage between upper and lower respiratory tract in man - the 'united airways hypothesis [20-22] - clinical development of AZD8848 became focused on intranasal administration.

AZD8848 has been shown to inhibit allergen responsiveness in patients with allergic rhinitis [23, 24]. The aim of this study was to examine the efficacy, safety and tolerability of intranasal AZD8848 $60 \mu \mathrm{g}$ administered once-weekly for 8 weeks in patients with physiciandiagnosed mild allergic asthma who were subsequently challenged with an inhaled allergen.

\section{Methods}

\section{Study participants}

The study enrolled male and female, non- and exsmokers aged 18-55 years with Global Initiative for Asthma (GINA)-defined mild-to-moderate asthma of $\geq 6$ months' duration and a positive skin prick test to grass, house dust mite or cat dander within the previous 24 months (clinicaltrials.gov identifier NCT00999466). The study was conducted with an initial safety and tolerability pilot study (AZD8848 $n=6$, placebo $n=3$ ), before initiating the main study. For inclusion in the main part of the study, patients had to demonstrate forced expiratory volume in $1 \mathrm{~s}\left(\mathrm{FEV}_{1}\right)>70 \%$ of predicted normal; an early asthmatic response (EAR) corresponding to $\geq 20 \%$ decrease in $\mathrm{FEV}_{1}$ within $2 \mathrm{~h}$ and a late asthmatic response (LAR) corresponding to $\geq 15 \%$ decrease in $\mathrm{FEV}_{1}$ between 4 and $10 \mathrm{~h}$ post-allergen challenge on 2 consecutive occasions and a methacholine provocation concentration leading to a $20 \%$ reduction in $\mathrm{FEV}_{1}\left(\mathrm{PC}_{20}\right)$ $<16 \mathrm{mg} / \mathrm{mL}$. The inhaled allergen to be used was one of those to which the patient had shown a positive response in the skin prick test. 
Patient exclusion criteria were: symptomatic allergic rhinitis (symptomatic allergic asthma was not excluded); previous treatment with inhaled corticosteroids \pm longacting $\beta_{2}$-agonists 4 weeks before the first study visit; use of antihistamines within 1 week or systemic corticosteroids within 6 weeks; respiratory tract infection within 2 weeks; and asthma exacerbation within 4 weeks before Visit 1.

Use of short-acting $\beta_{2}$-agonists was permitted except in the $8 \mathrm{~h}$ prior to spirometry at study visits. Inhaled corticosteroids (ICS) were stopped $>4$ weeks prior to the first methacholine challenge at Visit 1 (Fig. 1).

The study was approved by Wandsworth Research Ethics Committee, London. It was conducted according to the Declaration of Helsinki and in compliance with International Conference on Harmonisation/Good Clinical Practice. Written informed consent was obtained from all patients.

\section{Study design}

This was a double-blind, placebo-controlled, randomised, parallel-group study in patients with mild-to-moderate allergic asthma, conducted at two centres in the UK (Fig. 1 and Additional file 1: Figure S1). The study comprised an initial screening period of up to 8 weeks prior to randomisation, during which a methacholine challenge and an allergen challenge titration were performed.

Methacholine challenge was performed according to local Standard Operating Procedures.

Increasing doubling concentrations of Provocholine ${ }^{\circ}$ (methacholine), starting at $0.03125 \mathrm{mg} / \mathrm{mL}$ up to $16 \mathrm{mg} /$
$\mathrm{mL}$ during the screening period and up to $32 \mathrm{mg} / \mathrm{ml}$ during the treatment period were administered until $a \geq 20 \%$ fall in $\mathrm{FEV}_{1}$ from the post saline value was achieved. The five-breath dosimeter (five inhalations of methacholine administered) method was used. Salbutamol was administered to reverse bronchoconstriction at the conclusion of the test, if necessary. The participant's FEV ${ }_{1}$ was measured 15 min post-bronchodilator administration and then every 15 min until their $\mathrm{FEV}_{1}$ had returned to a value within $10 \%$ of their baseline. If the provocative concentration of methacholine causing a $20 \%$ fall in $\mathrm{FEV}_{1}$ was $>16 \mathrm{mg} / \mathrm{mL}$ the patient was excluded at Visit 1.

The allergen-challenge titration procedure performed during the screening period was conducted following the methods of Boulet et al., [25] to establish individually tolerable, repeatable, yet symptom-inducing doses of inhaled allergen [26]. Increasing doses of grass pollen, house dust mite or cat allergens (Aquagen ${ }^{\circ}$, Alk-Abello) were administered with a 30 min observation period in between each dose, until an EAR was observed. Following allergen challenge, the patient remained in the clinic for up to $12 \mathrm{~h}$, or overnight if there were any safety concerns, as judged by the Investigator. The cumulative dose of allergen that produced the desired effect of a fall in $\mathrm{FEV}_{1}$ of at least $20 \%$ in each patient was used again for that patient as a single bolus dose in two subsequent challenges, 1 week and 4 weeks after the last dose of treatment.

At least 1 week after the allergen challenge 51 patients entered the main treatment period, in which they were

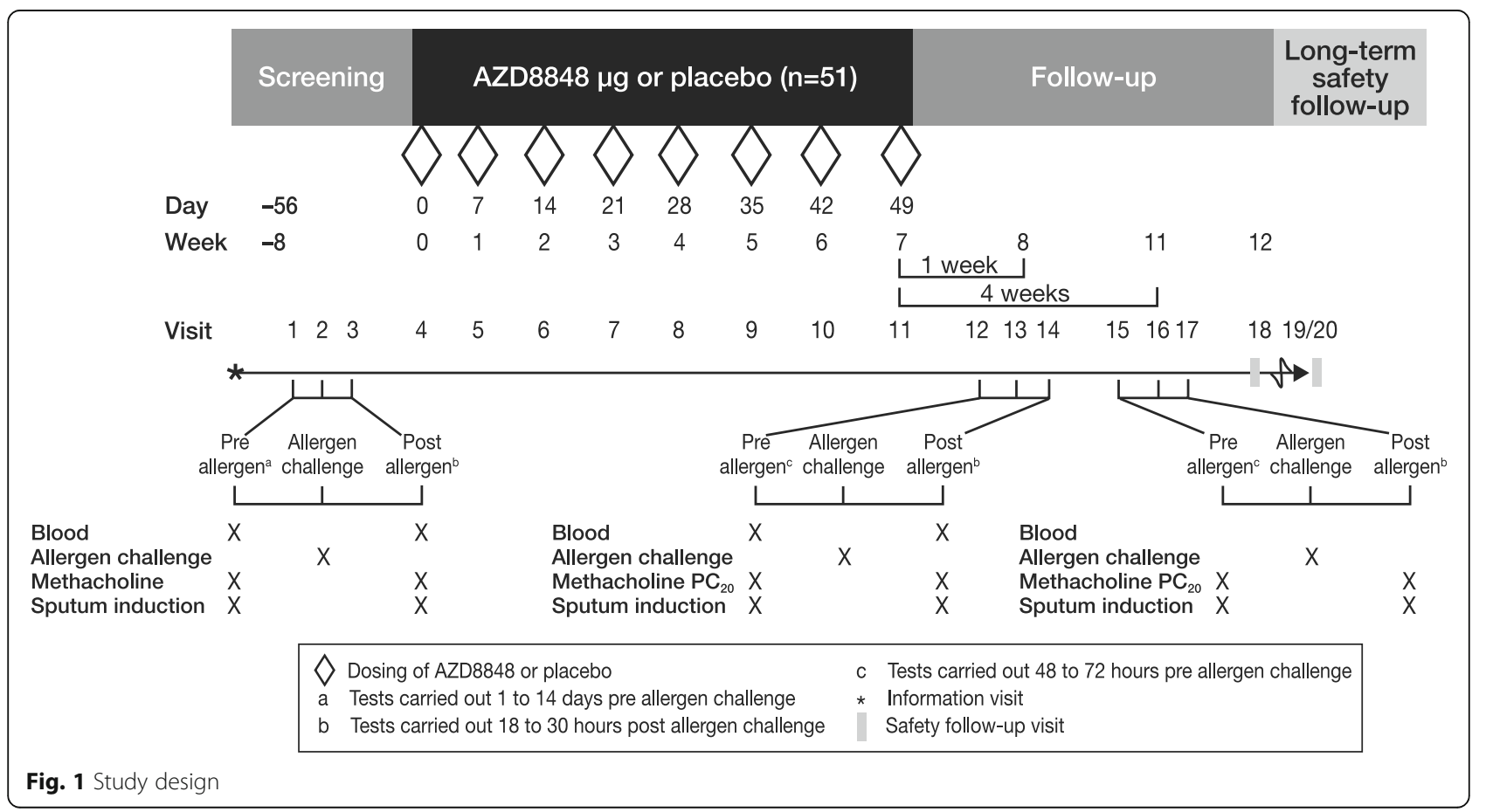


randomised to intranasal AZD8848 $60 \mu \mathrm{g}$ once-weekly or placebo for 8 weeks. Key efficacy assessments were performed at 1 and 4 weeks after the last dose of study drug.

\section{Study drug}

AZD8848 and matching placebo were administered as nasal spray solutions. The study product contained AZD8848 $\left(0.6 \mathrm{mg} \cdot \mathrm{mL}^{-1}\right)$ in a buffered sterile saline solution that was also used as a matching placebo. The products were provided in glass vials fitted with pump spray devices delivering $50 \mu \mathrm{L}$ per actuation. AZD8848 was administered in doses of $60 \mu \mathrm{g}$ (single $30 \mu \mathrm{g}$ spray into each nostril) and was only administered at the clinic visits, with a total of 8 doses administered over a 7 -week period. The dosing schedule used in this study was selected on the basis of Phase I/II clinical data [23, 24, 27]. Study drug administration was performed in clinic in a separate room equipped with a fume chamber. The individual nasal spray vials were primed before administration. As the no adverse effect level (NOAEL) for lung exposure was not available at the time of the study, the Investigator or study nurse instructed the patient to exhale orally against a resistance to close the connection between the lungs and the nasal airways. During this manoeuvre, the Investigator or study nurse administered the spray, ensuring delivery to nasal mucosa and avoiding administration of AZD8848 to the lungs.

Plasma concentrations representing the sum of the concentrations of AZD8848 and its main acid metabolite are shown in Additional file 1: Figure S3.

\section{Efficacy and safety assessments}

The primary outcome variable was the area under the curve (AUC)-based average mean fall from the pre-dose value of $\mathrm{FEV}_{1}$ during the $4-10 \mathrm{~h}$ interval post allergen assessment (LAR) at 1 week post-treatment. Serial measurements of $\mathrm{FEV}_{1}$ were performed every $30 \mathrm{~min}$. Data from the allergen challenges were summarized in terms of two mean $\mathrm{FEV}_{1}$ values, both computed from an area under the curve (trapezoidal rule), divided by observational time. Data were analysed both as $\mathrm{FEV}_{1}$ in litres and as percent change (in mean value) from the zero value, which was the first $\mathrm{FEV}_{1}$ measurement at the same visit measured prior to the allergen challenge. An additional allergen challenge at 4 weeks post-treatment was used to assess duration of efficacy. Secondary outcomes included EAR, measured by the average fall in $\mathrm{FEV}_{1}$ at $0-2 \mathrm{~h}$ post-allergen challenge; $\mathrm{PC}_{20}$ methacholine challenge (the provocative concentration of methacholine causing a $20 \%$ fall in $\mathrm{FEV}_{1}$ ) was used to assess allergen-induced AHR; analyses of biomarkers (including blood and sputum cytokines and cell counts) were carried out to explore the mechanism of action of
AZD8848. Baseline biomarkers including blood and sputum eosinophils were assessed at visit 1 and again after treatment. Safety and tolerability were assessed by adverse events (AEs) and vital signs/electrocardiographic parameters.

All samples were assayed for cytokines by multiplex, using MSD Proinflammatory II (Mesoscale Discovery) 4-plex plates in sputum and cell culture supernatants.

Sputum samples were induced at the first study visit before allergen challenge and again at the third study visit after allergen challenge, to provide baseline biomarker measurements, including eosinophils (Fig. 1). Sputum induction was repeated at Visit 12 and Visit 15, after the last dose of AZD8848 but before allergen challenge, and again at Visits 14 and 17, after the last dose and following allergen challenge to provide information on the duration of any observed effect of the study drug for 1 week and 4 weeks post-dosing. Sputum induction was performed $15 \mathrm{~min}$ after administration of $200 \mu \mathrm{g}$ of salbutamol, with $5 \%$ hypertonic saline inhaled for 5 mins before each of three cycles of expectoration.

\section{Statistical methods}

The primary outcome was evaluated using an analysis of variance (ANOVA) on the outcome variable with treatment as factor and pre-treatment (Visit 1) LAR as a covariate. The results were presented as a ratio of means. The secondary outcome variable, AUC-based EAR, was analysed in the same way as AUC-based LAR. All other secondary outcome variables such as biomarkers in sputum, and methacholine $\mathrm{PC}_{20}$ were measured both prior to allergen challenge and post challenge, at visits before treatment, and 1 and 4 weeks after treatment period. (Additional file 1: Figure S2). All of these secondary measurements were analysed using ANOVA. Methacholine $\mathrm{PC}_{20}$ data were estimated by loglinear interpolation: $\mathrm{PC}_{20}=\exp .\left(\ln _{i-1}+\left(\ln C_{i}-\ln C_{\mathrm{i}-1}\right)(20-\right.$ $\left.\left.\mathrm{R}_{i-1}\right) /\left(\mathrm{R} i-\mathrm{R}_{i-1}\right)\right)$. Safety and tolerability data were described using descriptive statistics. Sample size estimates found that 22 subjects per group would provide $90 \%$ power at $\alpha=0.05$ to detect a relative difference of $30 \%$ in $\mathrm{FEV}_{1}$ during the LAR following allergen challenge.

All patients who received at least 1 dose of randomised treatment and for whom any post-dose data were available were included in the efficacy and safety population (full analysis set).

\section{Results}

\section{Patient disposition}

A total of 51 patients were randomised and 43 patients (84\%) completed the study, 22 in the AZD8848 group and 21 in the placebo group (Additional file 1: Figure S1). The baseline and demographic characteristics of the patients were similar between those randomised to AZD8848 and placebo groups. Although the sputum 
eosinophil levels were similar between the two groups, the AZD8848 group had a slightly lower baseline eosinophil count (Table 1). A total of 8 patients discontinued from the study prematurely mainly due to adverse events (Table 2). The efficacy analysis set consisted of the 45 patients who were allocated treatment and had LAR data available.

\section{Efficacy}

\section{Late asthmatic response}

At baseline, post-allergen average LAR fall in $\mathrm{FEV}_{1}(\mathrm{SD})$ was $0.81 \mathrm{~L}(0.45)$ in the AZD8848 group and $1.01 \mathrm{~L}$ (0.78) in the placebo group. At 1 week after the last dose of treatment, AZD8848 significantly reduced average LAR fall in $\mathrm{FEV}_{1}$ by $27 \%$ compared with placebo $(p=$ 0.035; Fig. 2). This effect was not sustained at 4 weeks after the last dose of AZD8848 ( $p=0.349$; Fig. 2). AZD8848 showed a trend towards decreased maximal LAR fall in $\mathrm{FEV}_{1}$ versus placebo at 1 week after dosing, but this reduction did not reach statistical significance (18\% decrease vs placebo; $p=0.076$ ).

A post hoc subanalysis was conducted to examine postallergen LAR average fall in $\mathrm{FEV}_{1}$ according to baseline blood eosinophil levels recorded at visit 1 . A higher proportion of patients in the AZD8848 group had eosinophil levels of $<0.3 \times 10^{9} / \mathrm{L}$ (AZD8848 $n=19,73 \%$ vs placebo $n=12,48 \%$ ), which was reflected in the slight difference in baseline levels (AZD8848 $0.26 \times 10^{9} / \mathrm{L}$ vs placebo $0.35 \times 10^{9} / \mathrm{L}$ ) [28]. At 1 week after the last dose average LAR fall in $\mathrm{FEV}_{1}$ post allergen challenge was significantly reduced with AZD8848 compared with placebo in patients with baseline eosinophil levels of $\geq 0.3 \times 10^{9} / \mathrm{L}$ ( $48 \%$ reduction, $p=0.0447$ ). The cut off value for eosinophil was $0.3 \times 10^{9} / \mathrm{L}$ based on previous publications $[29,30]$. This

Table 1 Summary of demographic and clinical characteristics of study subjects at baseline

\begin{tabular}{|c|c|c|}
\hline Characteristics & AZD8848 $(n=26)$ & Placebo $(n=25)$ \\
\hline Male, $n(\%)$ & $19(73.1)$ & $18(72.0)$ \\
\hline Age (years) & 33.0 & 31.8 \\
\hline $\mathrm{BMI}\left(\mathrm{kg} \cdot \mathrm{m}^{2}\right)$ & 24.5 & 25.7 \\
\hline $\begin{array}{l}\text { Time since asthma diagnosis } \\
\text { (years) }\end{array}$ & 22.8 & 20.2 \\
\hline \multicolumn{3}{|l|}{$\mathrm{FEV}_{1}$} \\
\hline Litres (L) & 3.4 & 3.4 \\
\hline$\%$ predicted normal & 88.2 & 89.7 \\
\hline Blood eosinophils (X $\left.10^{9} / L\right)$ & 0.26 & 0.35 \\
\hline Methacholine $\mathrm{PC}_{20}(\mathrm{mg} / \mathrm{mL})$ & 0.564 & 0.609 \\
\hline $\begin{array}{l}\text { Sputum eosinophil count } \\
\text { (cells } \times 10^{6} / \mathrm{g} \text { ) }\end{array}$ & 0.13 & 0.12 \\
\hline
\end{tabular}

Data are presented as mean or \%, unless otherwise stated. BMI body mass index, $\mathrm{FEV}_{1}$ forced expiratory volume in $1 \mathrm{~s}$
Table 2 Number of patients who had an adverse event in any category, and number of adverse events by category, Main part

\begin{tabular}{|c|c|c|c|}
\hline & $\begin{array}{l}\text { AZD8848 } \\
(n=26)\end{array}$ & $\begin{array}{l}\text { Placebo } \\
(n=25)\end{array}$ & All $(n=51)$ \\
\hline \multicolumn{4}{|l|}{ Patients with an $A E^{\mathrm{a}}, n(\%)$} \\
\hline Any AEs & $22(85)$ & $22(88)$ & $44(86)$ \\
\hline Fatal SAEs & 0 & 0 & 0 \\
\hline Non-fatal SAEs & 0 & $1(4)$ & $1(2)$ \\
\hline $\mathrm{DAEs}^{\mathrm{b}}$ & $4(15)$ & $2(8)$ & $6(12)$ \\
\hline $\begin{array}{l}\text { Other significant adverse } \\
\text { events }\end{array}$ & 0 & 0 & 0 \\
\hline \multicolumn{4}{|l|}{ Total number of adverse events ${ }^{c}, n$} \\
\hline Any adverse events & 84 & 94 & 178 \\
\hline \multicolumn{4}{|l|}{ Maximum intensity } \\
\hline Mild & 65 & 70 & 135 \\
\hline Moderate & 16 & 23 & 39 \\
\hline Severe & 3 & 1 & 4 \\
\hline Maximum AEs/patient & 8 & 9 & 9 \\
\hline Causally related $\mathrm{AEs}^{\mathrm{d}}$ & 22 & 11 & 33 \\
\hline SAEs (fatal and non-fatal) & 0 & 1 & 1 \\
\hline $\begin{array}{l}\text { Causally related SAEs (fatal } \\
\text { and non-fatal) }\end{array}$ & 0 & 1 & 1 \\
\hline DAEs & 9 & 2 & 11 \\
\hline Other significant adverse events & 0 & 0 & 0 \\
\hline
\end{tabular}

apatients with multiple events in the same category are counted once in each category; ${ }^{\mathrm{b}}$ discontinuation of investigational product/study due to AEs; ${ }^{\mathrm{c}}$ multiple events with the same preferred term are counted once for each patient and category; ${ }^{d}$ as assessed by the investigator

Abbreviations: DAEs adverse events leading to treatment discontinuation, SAEs serious adverse events

effect was not maintained at 4 weeks post dosing. (Fig. 3) No significant reduction in LAR was observed in patients with baseline blood eosinophil levels of $<0.3 \times 10^{9} / \mathrm{L}$ ( $2 \%$ reduction, $p=0.93$ ) at 1 week or 4 weeks after treatment.

\section{Early asthmatic response}

The average EAR fall in $\mathrm{FEV}_{1}$ was numerically reduced by $18 \%$ with AZD8848 versus placebo at 1 week after the last dose, but this did not reach statistical significance $(p=0.28$; Fig. 4a). No effect was demonstrated on the repeat allergen challenge 4 weeks post-treatment (Fig. 4b).

\section{Airway hyper-responsiveness}

AZD8848 attenuated the methacholine-induced AHR compared with placebo after the allergen challenge performed 1 week after the last dose (treatment ratio: 2.20 (95\% CI: 1.12, 4.33) $p=0.024$ ). No effect was observed with AZD8848 on the pre-allergen methacholine challenge at 1 week after the last dose. There was no effect of AZD8848 on AHR at week 4 after the last dose. 


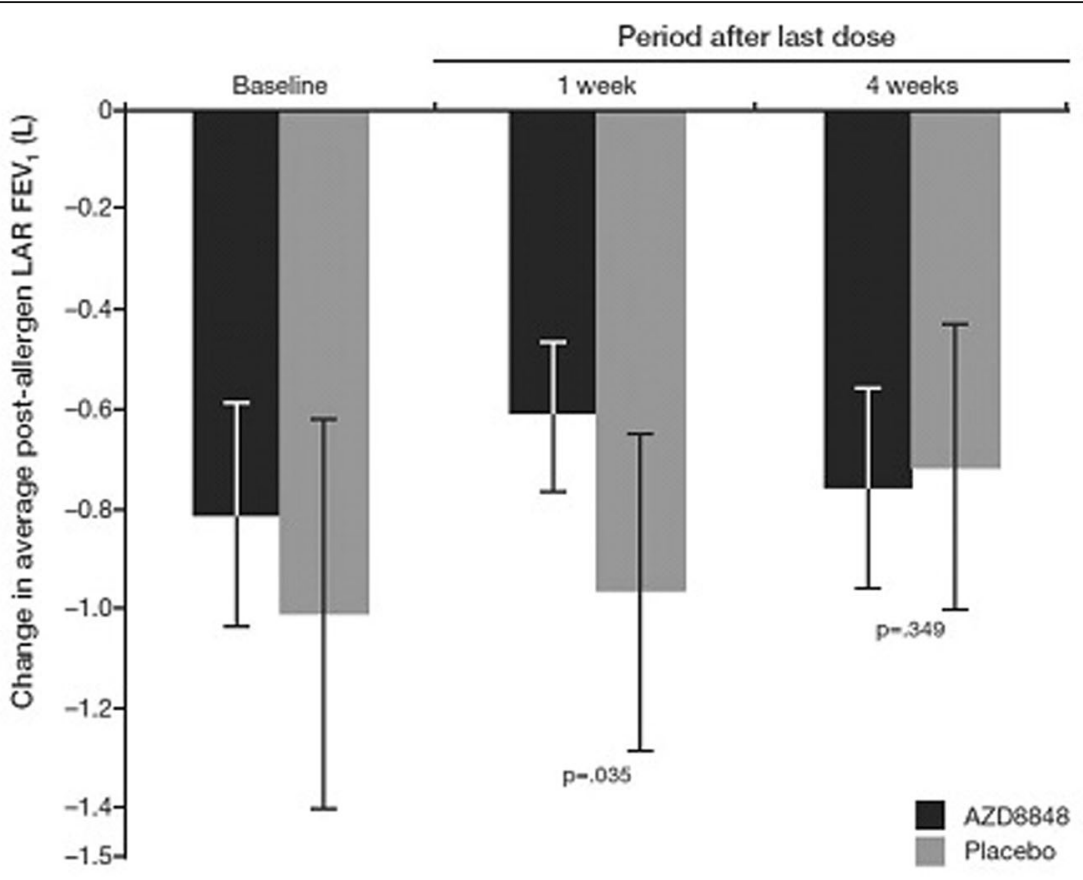

AUC-based LAR $=$ AUC A.20k $_{4}$ computed using the trapezoidal formula, divided by time.

AUC, area under the curve; FEV ${ }_{2}$ forced expiratory volume in 1 second; LAR, late asthmatic reaction

Fig. 2 Average change in lung function over 4-10 h after allergen challenge (LAR). Error bars represent \pm standard deviation (SD)

\section{Exploratory biomarkers}

There were no significant changes from baseline (Visit 1) in plasma cytokine, sputum Th2 cytokine or sputum eosinophil levels in either the AZD8848 or placebo groups at 1 and 4 weeks after the last dose of AZD8848, with no significant difference between the groups. A trend towards a reduction in the sputum Th2 cytokines IL-5, IL-13 and in sputum eosinophils was observed 1 week after the last dose of AZD8848 compared with placebo prior to allergen challenge (Fig. 5; $p=0.097, p=0.054$ and $p=0.068$ respectively; Additional file 1: Table S1 and Figure S2). As expected, there was a robust Th2 cytokine response postallergen challenge in both the blood and sputum samples. However, there was no significant change from baseline in this response 1 week after cessation of dosing with AZD8848 or placebo. In addition, there appeared to be no differences in gene expression changes locally or systemically between the AZD8848 group and placebo group 1 week post-dosing before or after allergen challenge. In an allergen recall assay, 37 patients provided samples and the expected allergen-induced increase in Th2 cytokines (IL-5 and IL-13) was observed in PBMC prepared from the predose blood samples from the AZD8848 or placebo groups, with no significant increase in either IL-10 or IFN $\gamma$, indicating a good biomarker response in the house dust mitesensitive individuals. There was no significant change in this response observed 1 week post-dosing with either AZD8848 or placebo.

\section{Safety and tolerability}

AZD8848 was generally well tolerated, with influenza-like symptoms reported more frequently during the AZD8848 treatment period (58\%), compared with placebo (24\%) (Table 2). No deaths occurred during the study and the only serious AE reported (bacterial tonsillitis) occurred in the placebo group. AEs leading to discontinuation of study treatment (DAEs) occurred in 15\% of AZD8848 and 8\% of placebo recipients. One patient in each treatment group discontinued due to asthma related events and 1 patient in each treatment group discontinued due to raised transaminases. In the AZD8848 group, other DAEs included pyrexia, back pain and loss of consciousness for $20 \mathrm{~s}$ in a female aged 30 years, arthralgia, somnolence and headache in a 24-year-old male. The vast majority of AEs were of mild or moderate intensity, with headache, nasal dryness, arthralgia and pyrexia the most commonly reported AEs related to AZD8848 treatment (Table 3). Nasal symptoms (including epistaxis, rhinorrhoea, nasal congestion/obstruction, sneezing, nasal dryness, and nasal ulcer) were equally distributed between treatments. No clinically relevant changes in vital signs/electrocardiographic parameters were observed. 

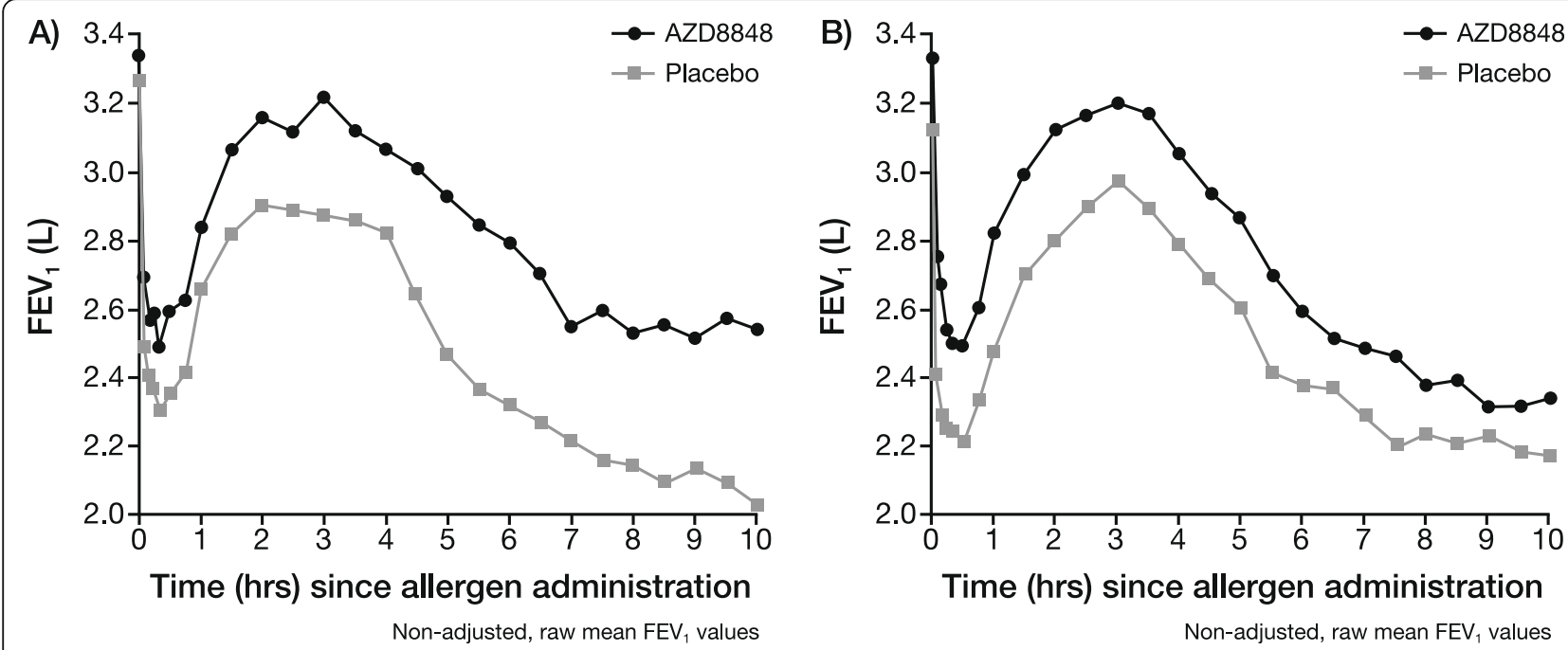

Fig. 3 Geometric mean $\mathrm{FEV}_{1}$ after allergen challenge a) 1 week and $\left.\mathbf{b}\right) 4$ weeks after end of treatment

\section{Discussion}

This study in patients with allergic asthma demonstrated that intranasal administration of the TLR7 agonist AZD8848 attenuated the average post-allergen LAR fall in $\mathrm{FEV}_{1}$ and prevented an increase in AHR following allergen challenge 1 week after the last dose. AZD8848 was generally well tolerated.

Currently available asthma therapies, although effective in the majority of patients, do not provide adequate asthma control in a substantial number of patients, require chronic dosing and have potential side effects, particularly at higher doses [31]. TLR7 agonists have potential as a new treatment option for allergic asthma through the stimulation of Th1/Th0 effector cells, thereby attenuating allergen-specific Th2 cells $[15,16]$. A potential drawback to this approach has been the systemic induction of proinflammatory cytokines [32], resulting in influenza-type side effects $[33,34]$. To overcome these problems, an antedrug approach has been employed.

AZD8848 is a metabolically labile ester with a plasma half-life $\left(t_{1 / 2}\right)$ of $2-3 \mathrm{~min}$, which is rapidly converted to a weakly active metabolite in the plasma with a $t_{1 / 2}$ of 36 min [35]. The hypothesis is that there would be minimal systemic exposure and limited IFN I immune activation due to this brief half-life, resulting in a reduced incidence of side effects. In this study the drug was administered locally to the nose, avoiding inhalation to the lung, but with therapeutic effects observed in the lung and minimal systemic exposure.

Preclinical studies in murine models [35, 36] demonstrated that intranasal administration of AZD8848 can confer sustained protection against allergen challenge. The allergen challenge model in man is an important predictor of subsequent efficacy in the treatment of asthma [37]. Inhaled steroids have been shown to inhibit the LAR $\left(\mathrm{AUC}_{3-10}\right)$ by $50-80 \%$ after a single dose, but multiple doses over several weeks are required to demonstrate inhibition of both EAR and LAR [38]. Gauvreau et al. reported a lack of effect on allergen challenge of a novel immunomodulatory agent which induced IFN gamma via TLR9 receptor stimulation [39]. However, this mechanism has a restricted range of stimulatory effects on immune cells in man and is in contrast with AZD8848 which is a TLR7 agonist.

AZD8848 is the first intra-nasally administered immunomodulatory compound shown to attenuate allergeninduced LAR and AHR at 1 week after treatment. These effects were not observed at 4 weeks after the final dose. Further studies are needed to evaluate the potential duration of effect of AZD8848 at different dosing frequencies and durations and to explore if it may be possible to reset the immune system to reduce or minimise the allergic response with this treatment approach.

A subgroup analysis revealed that the effect on LAR in AZD8848-treated patients was more pronounced in the higher plasma eosinophil group $\left(\geq 0.3 \times 10^{9} / \mathrm{L}\right)$, and was greater than the reported outcome for the full study population. These results highlight the importance of identifying different phenotypes in asthma. These results are also consistent with reports of reduced allergen responsiveness with AZD8848 up to 8 days after final dosing in patients with allergic rhinitis [24].

Administration of AZD8848 directly to the lung has previously been shown to inhibit eosinophilia and IL-13 levels for up to 4 weeks post-treatment following ovalbumin challenge in the Brown Norway rat [35]. In the current study there were no significant changes observed in sputum cytokine or eosinophil counts with intranasal 

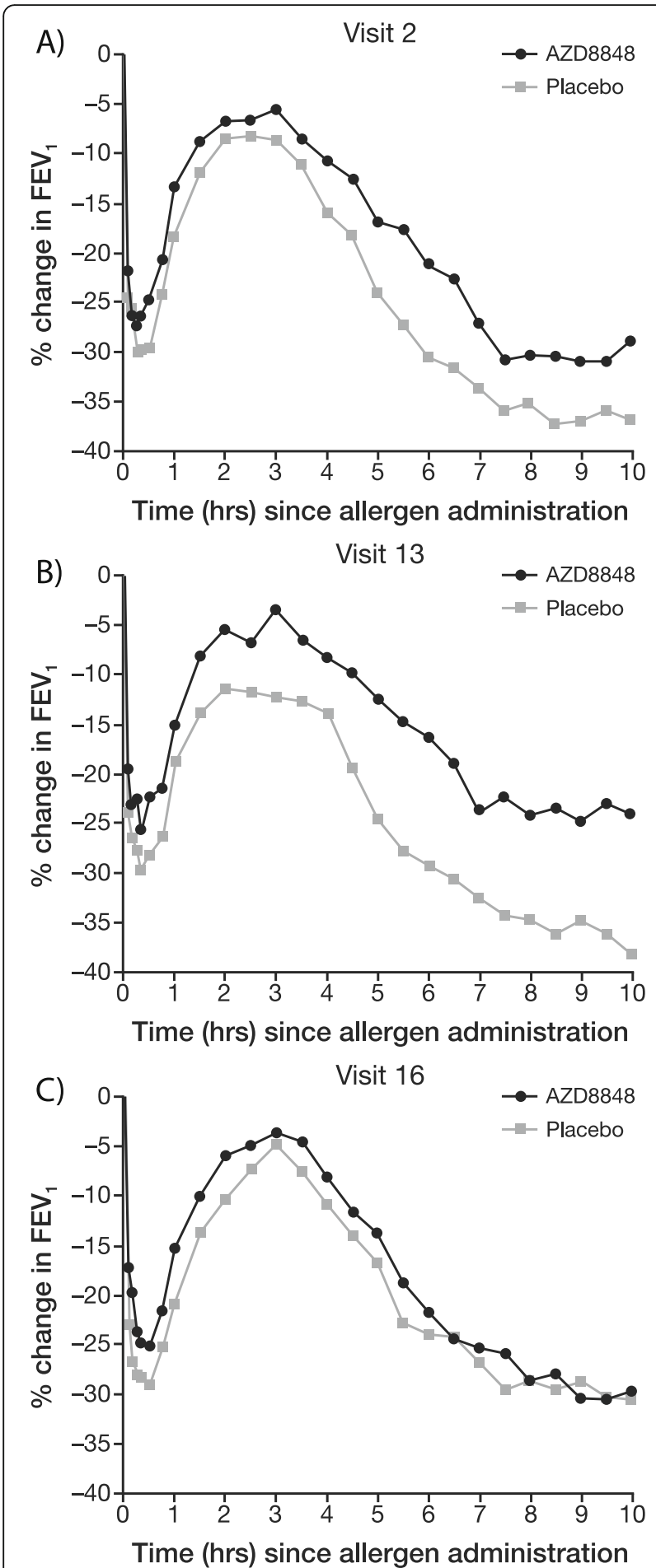

Fig. 4 Percentage changes in $\mathrm{FEV}_{1}$ at a) baseline, b) 1 week and $\mathbf{c}$ ) 4 weeks after end of treatment

AZD8848 treatment 1 week post-dosing, either before or after allergen challenge. Although there was a trend towards a reduction in Th2 cytokines and sputum eosinophils prior to allergen challenge 1 week after the last dose, this did not reach statistical significance. However, the range of all sputum cell data was $n=12$ to 19 per group from a total number of subjects of $n=25$ (placebo) or $n=26$ (AZD8848). In our opinion, this reduced number of sputum samples in each respective treatment group was too low to demonstrate statistical difference between the groups.

The observed trend of both reduced IL-13 and reduced eosinophils, together with the pre-clinical results, suggest that TLR7 agonists may suppress the Th2 immune state in asthmatic subjects challenged with allergen. There were no changes in IFNregulated gene expression 1 week post-dosing in the current study, which is in keeping with previous clinical studies [24]. The lack of effect on PBMC response in the allergen recall experiment suggests that AZD8848 did not provide protection from the allergic inflammation induced by house dust mite allergen at 1 week post-dosing. The primary outcome variable for the allergen challenge test was the area under the curve (AUC). Power calculations for other endpoints were not performed, so the sample size was not based on a formal power calculation. Instead, a practical approach was used to obtain as many samples as feasible within the study. The absence of significant effects on the exploratory biomarkers studied at 1 week post-dosing indicates that there was no unwanted induction of systemic Th1 cytokines by administration of AZD8848. We did not design the study to assess upregulation of TRL7-mediated Th1 responses, but we have assumed that the inhibition of LAR observed here was due to this mechanism.

The cellular and molecular mechanisms by which a brief intranasal exposure of a TLR7 agonist can produce long-term immune effects in the lung remain speculative although the united airways hypothesis may be involved. The precise mechanism by which TLR7 agonists abrogate the LAR in allergic asthmatics also remains to be elucidated. It is possible that antigen presenting cells such as dendritic cells [40] or certain macrophages (e.g. M2 subtypes) [41, 42] may traffic to lymph nodes after exogenous exposure in the nose. Alternatively, innate lymphoid cells may be involved. Of the three sub-types of ILC, ILC2 may be involved in generating Th2 responses when activated by epithelial-derived cytokines such as thymic stromal lymphopoietin (TSLP), whereas ILC1 type cells may be stimulated by TLR7 agonists to reverse this trend towards the Th2 asthma phenotype by releasing IFN $\gamma$. TSLP appears to be an important common pathway between airway epithelium and inflammatory cascades $[43,44]$ and counts of ILC1 cells, such as NK cells, have been found to be low in patients with severe asthma [45]. 


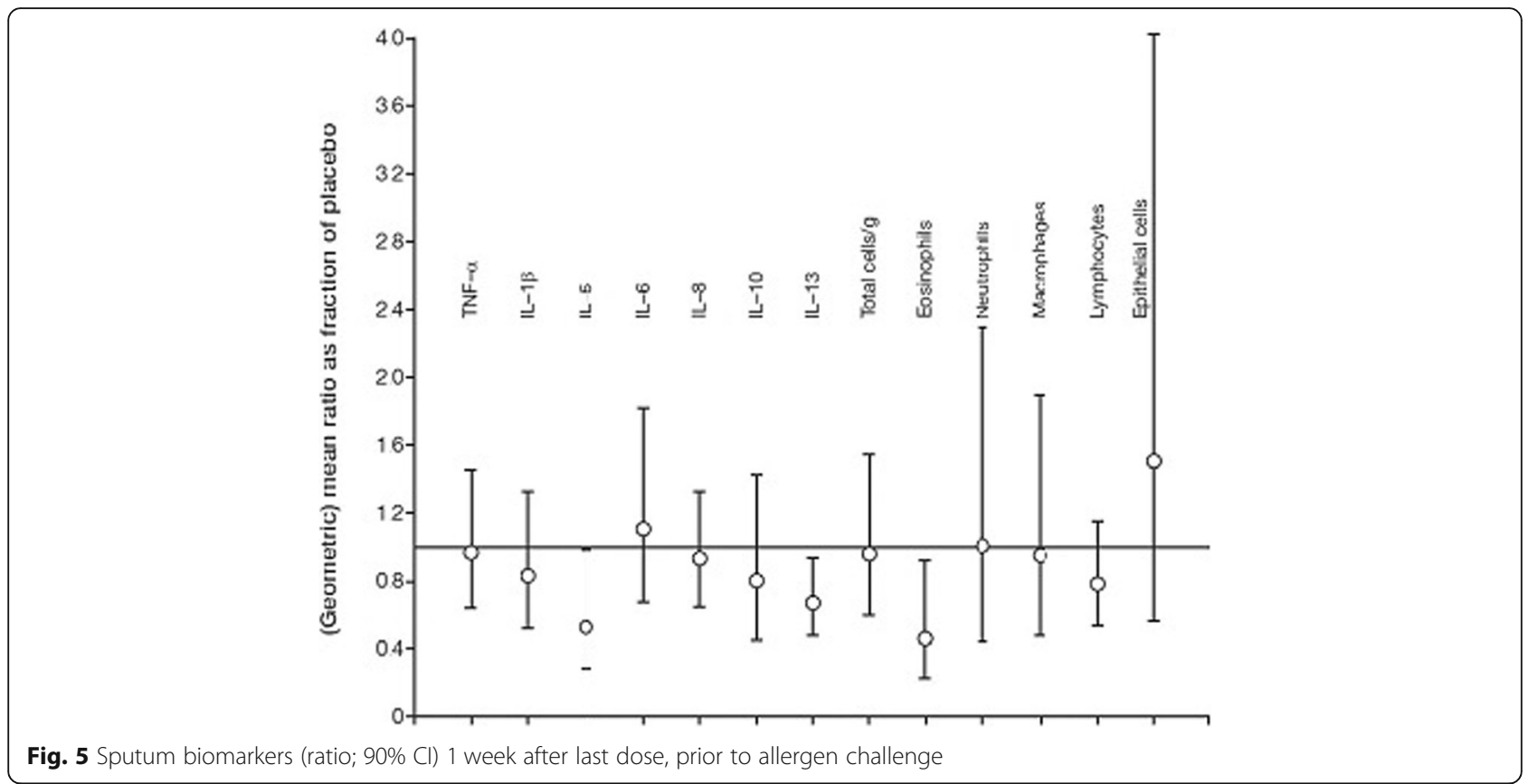

TLR7 activation induces transcription of NF-kB [46] with induction of an innate immune response; typically production of IFNY and pro-inflammatory cytokines (IL-1 $\beta)$. The upregulation of Th1 responses may alter the Th1 versus Th2 [47] immune state in susceptible asthma subjects and result in abrogation of allergic Th2 responses induced by allergen [48]. Nevertheless, in this study the effects of AZD8848, whilst persisting for 1 week beyond the end of dosing, were not sustained for the relatively longer period seen in rodent models. Direct stimulation of TLR7 in the lung itself may be needed to effect such a sustained change in the immune response. It remains to be established whether administration of AZD8848 directly to the human lung might induce an effect equivalent in magnitude and duration to that seen in rodent models of inflammatory disease.

Table 3 Adverse events (AEs) considered related to study drug (reported in $\geq 2$ patients)

\begin{tabular}{lll}
\hline Adverse event & AZD8848 $(n=26)$ & Placebo $(n=25)$ \\
\hline Any drug-related AEs & $22(85)$ & $11(44)$ \\
Headache & $4(15)$ & 0 \\
Nasal dryness & $2(8)$ & $1(4)$ \\
Rhinorrhoea & 0 & $2(8)$ \\
Arthralgia & $2(8)$ & 0 \\
Pyrexia & $2(8)$ & 0 \\
\hline
\end{tabular}

Data are presented as $n(\%)$
AZD8848, administered once-weekly during an 8week treatment period was generally well tolerated. As reported in other clinical studies, [24] symptoms possibly linked to activation of the IFN $\alpha$ pathway were more prevalent after administration of AZD8848 compared with placebo, but these were generally mild in intensity. Increased nasal side effects have previously been reported with AZD8848 treatment, notably at doses of $100 \mu \mathrm{g}$ and above, [24] or with more frequent dosing [27]. In the present study, at the lower dose of $60 \mu \mathrm{g}$ once-weekly, the overall incidence of nasal symptoms was similar in the active and placebo-treated groups and the incidence of mucosal ulceration was limited to a single individual in the active treatment group.

\section{Conclusions}

We conclude that intranasal AZD8848 attenuated allergen-induced LAR and prevented allergen-induced increases in AHR in patients with allergic asthma at 1 week post-treatment. When administered onceweekly for 8 weeks, AZD8848 was generally well tolerated. This study demonstrates that intranasal administration of a TLR7 agonist, such as AZD8848, can ameliorate an allergen-induced response in the lower airways, carried out one week following the cessation of dosing.

All other allergen studies conduct the challenge during the dosing period and the intriguing finding 
here is that there is significant amelioration of the allergen challenge conducted at least one week after the last dose at a time when there were no detectable drug levels according to the pharmacokinetic analysis. This implies that the TLR7 agonist AZD8848 has an immunomodulatory effect that persists after the known pharmacokinetic actions of the drug. The immunomodulatory effect was detected three weeks after dosing in the final allergen challenge, albeit the effects were much weaker at this time point and failed to reach significance.

\section{Supplementary information}

Supplementary information accompanies this paper at https://doi.org/10. 1186/s12931-019-1252-2.

Additional file 1: Table S1. Treatment effect on sputum biomarkers at visit 12 which had to take place 48 to 72 h prior to Visit 13, which took place 1 week ( \pm 1 day) after the last dose. Figure S1. Consort flow diagram. Figure S2. Sputum cytokine levels measured pre- and postallergen challenge before and after dosing with intranasal AZD8848 or placebo. ( $n=12-19$ for the various biomarker analyses). Figure S3. Individual AZD8848 concentration data

\section{Abbreviations}

AE: Adverse event; AHR: Airway hyper-responsiveness; ANOVA: Analysis of variance; $A \cup C$ : Area under the curve; $A_{U} C_{3-10}$ : Area under the curve from $3 \mathrm{~h}$ to $10 \mathrm{~h}$; DAE: Adverse event leading to discontinuation; EAR: Early asthmatic response; $\mathrm{FEV}_{1}$ : Forced expiratory volume in $1 \mathrm{~s}$; ICS: Inhaled corticosteroids; IFNs: Interferons (a group of signalling proteins); IFNa: Type I interferonalpha; IFNy: Type II interferon gamma; IL-4, IL-5, IL-9, IL-10, IL-13: Interleukin-4, $-5,-9,-10$ or - 13; ILC: Innate Iymphoid cell; IRAK-1: Interleukin-1 receptorassociated kinase 1; IRAK-4: Interleukin-1 receptor-associated kinase 4; IRF7: Interferon regulatory factor 7; LAR: Late asthmatic response; MyD88: Myeloid differentiation primary response 88 (a universal adapte protein used by TLRs to activate transcription factor NF-KB.); NF-kB: Nuclear factor kappa-light-chain-enhancer of activated B cells, a transcription factor found in all nucleated cell types); NK: Natural killer cell; NOAEL: No adverse effect level; PAMPs: Pathogen-associated molecular patterns;

PBMC: Peripheral blood mononuclear cell; $\mathrm{PC}_{20}$ : A provocation concentration leading to a $20 \%$ reduction in $\mathrm{FEV}_{1}$; ssRNA: Single-stranded ribonucleic acid; T cells: T lymphocytes; Th1: T-helper 1 cells (primarily produce interferon (IFNy and IL-2); Th2: T-helper cells (produce IL-4, IL-5, IL-6, IL-10, and IL-13); TLR: Toll-like receptors (single, membrane-spanning, non-catalytic receptors); TRAF6: TNF receptor-associated factor 6; $T_{\text {reg: }}$ : Regulatory T-cells (inhibit T cell proliferation and cytokine production); TSLP: Thymic stromal lymphopoietin

\section{Acknowledgements}

The authors would like to thank the study team at AstraZeneca and the two participating sites; Anders Källen for statistical analysis of data; Mike Dymond for statistical analysis of biomarker data; Andy Walding and Carolyn Jones for technical assistance with the gene expression data. BL would like to thank Professor Peter Barnes (FRS) for helpful discussions on study design and scientific contribution. Medical writing assistance was provided by David Candlish and Helen Brereton of inScience Communications, Springer Healthcare Ltd., UK, in accordance with Good Publication Practice (GPP3) guidelines (http://www.ismpp.org/gpp3), and this was funded by AstraZeneca.

\section{Authors' contributions}

All authors participated in the design, recruitment and/or conduct of the study and contributed to data interpretation and conceiving, writing and revising the manuscript and were involved at all stages in the development of the manuscript. All authors read and approved the final manuscript.

\section{Funding}

The work described in this paper was supported through a collaboration between AstraZeneca and Sumitomo Dainippon Pharma.

\section{Availability of data and materials}

The datasets generated and/or analysed during the current study are available in the AstraZeneca repository, https://astrazenecagrouptrials. pharmacm.com/ST/Submission/Niew?id=275

\section{Ethics approval and consent to participate}

The study was approved by Wandsworth Research Ethics Committee, London. It was conducted according to the Declaration of Helsinki and in compliance with International Conference on Harmonisation/Good Clinical Practice. Written informed consent was obtained from all patients.

\section{Consent for publication}

All authors have provided their consent for publication of this manuscript.

\section{Competing interests}

$\mathrm{BL}$ has received research funding from Astra Zeneca Aquinox Pharmaceuticals, AstraZeneca, Elevation Pharma, Chiesi, Daiichi-Sankyo, GlaxoSmithKline, Merck, Biota Pharma and Pfizer; DS has received sponsorship to attend international meetings, honoraria for lecturing or attending advisory boards and research grants from various pharmaceutical companies including Almirall, AstraZeneca, Boehringer Ingelheim, Chiesi, Genentech, GlaxoSmithKline, Glenmark, Johnson and Johnson, Merck, NAPP, Novartis, Pfizer, Skyepharma, Takeda, Teva, Therevance and Verona; SL was an employee of AstraZeneca at the time of this work was carried out and holds shares in the company; LE was an employee of AstraZeneca and holds shares in the company; GA is an employee of AstraZeneca and holds shares in the company; BY was an employee of AstraZeneca at the time this work was carried out; $\mathrm{BOC}$ has received research funding from Aquinox Pharmaceuticals, AstraZeneca, Chiesi and GlaxoSmithKline.

\section{Author details}

${ }^{1}$ Respiratory Clinical Trials Ltd, Queen Anne Street Medical Centre, 18-22 Queen Anne Street, London W1G 8HU, UK. ${ }^{2}$ Medicines Evaluation Unit, University of Manchester, University Hospital of South Manchester, Manchester, UK. ${ }^{3}$ Biopharmaceuticals R\&D, Late-stage Development RIA, AstraZeneca, Gothenburg, Sweden. ${ }^{4}$ Early Clinical Development, AstraZeneca R\&D, Mölndal, Sweden. ${ }^{5}$ Discovery Bioscience, AstraZeneca R\&D, Loughborough, UK.

Received: 26 March 2019 Accepted: 28 November 2019 Published online: 19 December 2019

\section{References}

1. Bjerg A, Ekerljung L, Middelveld R, Dahlen SE, Forsberg B, Franklin K, Larsson K, Lotvall J, Olafsdottir IS, Toren K, et al. Increased prevalence of symptoms of rhinitis but not of asthma between 1990 and 2008 in Swedish adults: comparisons of the ECRHS and GA(2)LEN surveys. PLoS One. 2011;6:e16082.

2. Braun-Fahrlander C, Riedler J, Herz U, Eder W, Waser M, Grize L, Maisch S, Carr D, Gerlach F, Bufe A, et al. Environmental exposure to endotoxin and its relation to asthma in school-age children. N Engl J Med. 2002;347:869-77.

3. Strachan DP. Hay fever, hygiene, and household size. BMJ. 1989;299: 1259-60.

4. Zhu J, Yamane H, Paul WE. Differentiation of effector CD4 T cell populations (*). Annu Rev Immunol. 2010;28:445-89.

5. Chatila TA. Innate immunity in asthma. N Engl J Med. 2016;375:477-79.

6. Stein MM, Hrusch CL, Gozdz J, Igartua C, Pivniouk V, Murray SE, Ledford JG, Marques dos Santos M, Anderson RL, Metwali N, et al. Innate immunity and asthma risk in Amish and Hutterite farm children. N Engl J Med. 2016;375: 411-21.

7. Barnes PJ. The cytokine network in asthma and chronic obstructive pulmonary disease. J Clin Invest. 2008;118:3546-56.

8. Kay AB. The role of eosinophils in the pathogenesis of asthma. Trends Mol Med. 2005;11:148-52.

9. Lloyd CM, Hawrylowicz CM. Regulatory T cells in asthma. Immun. 2009;31:438-49.

10. O'Garra A. Cytokines induce the development of functionally heterogeneous T helper cell subsets. Immun. 1998;8:275-83. 
11. Kawai T, Akira S. Innate immune recognition of viral infection. Nat Immunol. 2006;7:131-37.

12. Schaub B, Lauener $R$, von Mutius $E$. The many faces of the hygiene hypothesis. J Allergy Clin Immunol. 2006;117:969-77 quiz 978.

13. Lund JM, Alexopoulou L, Sato A, Karow M, Adams NC, Gale NW, Iwasaki A, Flavell RA. Recognition of single-stranded RNA viruses by toll-like receptor 7 . Proc Natl Acad Sci U S A. 2004;101:5598-603.

14. Akira S, Uematsu S, Takeuchi O. Pathogen recognition and innate immunity. Cell. 2006;124:783-801.

15. Biffen M, Matsui H, Edwards S, Leishman AJ, Eiho K, Holness E, Satterthwaite G, Doyle I, Wada H, Fraser NJ, et al. Biological characterization of a novel class of toll-like receptor 7 agonists designed to have reduced systemic activity. Br J Pharmacol. 2012;166:573-86.

16. Moisan J, Camateros $P$, Thuraisingam T, Marion D, Koohsari H, Martin P, Boghdady ML, Ding A, Gaestel M, Guiot MC, et al. TLR7 ligand prevents allergen-induced airway hyperresponsiveness and eosinophilia in allergic asthma by a MYD88-dependent and MK2-independent pathway. Am J Physiol Lung Cell Mol Physiol. 2006;290:L987-95.

17. Sel S, Wegmann M, Bauer S, Garn H, Alber G, Renz H. Immunomodulatory effects of viral TLR ligands on experimental asthma depend on the additive effects of IL-12 and IL-10. J Immunol. 2007:178:7805-13.

18. Huang T-J, MacAry PA, Eynott P, Moussavi A, Daniel KC, Askenase PW, Kemeny DM, Chung KF. Allergen-specific Th1 cells counteract efferent Th2 cell-dependent bronchial hyperresponsiveness and eosinophilic inflammation partly via IFN-ץ. J Immunol. 2001;166:207-17.

19. Khan MOF, Park KK, Lee HJ. Antedrugs: an approach to safer drugs. Curr Med Chem. 2005;12:2227-39.

20. Braunstahl GJ. The united airways concept: from bench to bedside. Monaldi Arch Chest Dis. 2007;67:95-101

21. Giavina-Bianchi P, Aun MV, Takejima P, Kalil J, Agondi RC. United airway disease: current perspectives. J Asthma Allergy. 2016;9:93-100.

22. Licari A, Castagnoli R, Denicolò C, Rossini L, Marseglia A, Marseglia G. The nose and the lung: united airway disease? Front Pediatr. 2017:5:44

23. Greiff $L$, Ahlstrom-Amenuelsson A, Alenas M, Almqvist $G$, Andersson M, Cervin A, Dolata J, Lindgren S, Martensson A, Young B, Widegren H: Biological effects and clinical efficacy of a topical Toll-like receptor 7 agonist in patients with seasonal allergic rhinitis Inflamm Res. 2015;64(11):903-15

24. Greiff L, Cervin A, Ahlstrom-Emanuelsson C, Almqvist G, Andersson M, Dolata J, Eriksson L, Hogestatt ED, Kallen A, Norlen P, et al. Repeated intranasal TLR7 stimulation reduces allergen responsiveness in allergic rhinitis. Respir Res. 2012;13:53.

25. Boulet L, Gauvreau G, Boulay M, O'Byrne P, Cockcroft D. The allergen bronchoprovocation model: an important tool for the investigation of new asthma anti-inflammatory therapies. Allergy. 2007;62:1101-10.

26. Singh D, Cadden P, Hunter M, Pearce Collins L, Perkins M, Pettipher R, Townsend E, Vinall $S, O^{\prime}$ Connor B. Inhibition of the asthmatic allergen challenge response by the CRTH2 antagonist OC000459. Eur Respir J. 2013;41:46-52.

27. Greiff L, Cervin A, Lindgren S, Alenäs M, Almqvist G, Young B. Efficacy and tolerability of the Toll-like receptor 7 agonist AZD8848 in patients with seasonal allergic rhinitis. Am J Respir Crit Care Med. 2012;185:A4189.

28. Fowler SJ, Tavernier G, Niven R. High blood eosinophil counts predict sputum eosinophilia in patients with severe asthma. J Allergy Clin Immunol. 2015;135:822-824 e822.

29. Pavord ID, Korn S, Howarth P, Bleecker ER, Buhl R, Keene ON, Ortega H, Chanez P. Mepolizumab for severe eosinophilic asthma (DREAM): a multicentre, double-blind, placebo-controlled trial. Lancet. 2012;380:651-59.

30. Menzella F, Lusuardi M, Galeone C, Taddei S, Facciolongo N, Zucchi L. Mepolizumab for severe refractory eosinophilic asthma: evidence to date and clinical potential. Ther Adv Chronic Dis. 2016;7:260-77.

31. Storms WW. Unmet needs in the treatment of allergic asthma: potential role of novel biologic therapies. J Manag Care Pharm. 2003;9:534-43.

32. Vultaggio A, Nencini F, Fitch PM, Fili L, Maggi L, Fanti $P$, deVries a, Beccastrini E, Palandri F, Manuelli C, et al. Modified adenine (9-benzyl-2butoxy-8-hydroxyadenine) redirects Th2-mediated murine lung inflammation by triggering TLR7. J Immunol. 2009;182:880-89.

33. Dudek AZ, Yunis C, Harrison LI, Kumar S, Hawkinson R, Cooley S, Vasilakos JP, Gorski KS, Miller JS. First in human phase I trial of 852A, a novel systemic toll-like receptor 7 agonist, to activate innate immune responses in patients with advanced cancer. Clin Cancer Res. 2007;13:7119-25.

34. Pockros PJ, Guyader D, Patton H, Tong MJ, Wright T, McHutchison JG, Meng TC. Oral resiquimod in chronic HCV infection: safety and efficacy in 2 placebo-controlled, double-blind phase lla studies. J Hepatol. 2007:47:174-82

35. Bell J, Britt J, Biffen M, Ferguson D, Aoki M, Eiho K, Bahl AK, Takaku H, Murray C. AZD8848/DSP-3025 is a novel potent TLR7 agonist ante-drug that demonstrates negligible systemic activity and a prolonged period of control after cessation of weekly dosing in a Brown Norway rat ovalbumin challenge model. Am J Respir Crit Care Med. 2010;181:A5688.

36. Aoki M, Bell JP, Ikeda K, Onishi M, Eiho K, Tomizawa H, Takaku H, Kitaura M. Weekly dosing of AZD8848/DSP-3025, a novel TLR7 agonist ante-drug, demonstrates a prolonged period of control against markers of pulmonary inflammation in an allergen challenge model in the mouse. Am J Respir Crit Care Med. 2010;181:A5689.

37. O'Byrne PM, Gauvreau GM, Brannan JD. Provoked models of asthma: what have we learnt? Clin Exp Allergy. 2009;39:181-92.

38. Weersink EJM, Postma DS, Aalbers R, de Monchy JGR. Early and late asthmatic reaction after allergen challenge. Respir Med. 1994;88:103-14.

39. Gauvreau GM, Hessel EM, Boulet LP, Coffman RL, O'Byrne PM. Immunostimulatory sequences regulate interferon-inducible genes but not allergic airway responses. Am J Respir Crit Care Med. 2006;174:15-20.

40. Bao M, Liu YJ. Regulation of TLR7/9 signaling in plasmacytoid dendritic cells. Protein Cell. 2013:4:40-52.

41. Gordon S, Martinez FO. Alternative activation of macrophages: mechanism and functions. Immun. 2010;32:593-604

42. Mosser DM, Edwards JP. Exploring the full spectrum of macrophage activation. Nat Rev Immunol. 2008;8:958-69.

43. Lv J, Yu Q, Lv J, Di C, Lin X, Su W, Wu M, Xia Z. Airway epithelial TSLP production of TLR2 drives type 2 immunity in allergic airway inflammation. Eur J Immunol. 2018. Epub ahead of print.

44. Gauvreau GM, O'Byrne PM, Boulet LP, Wang Y, Cockcroft D, Bigler J, M. F J, Boedigheimer M, Davis BE, Dias C, et al. Effects of an anti-TSLP antibody on allergen-induced asthmatic responses. N Engl J Med. 2014;370:2102-10.

45. Barnig C, Cernadas M, Dutile S, Liu X, Perrella MA, Kazani S, Wechsler ME, Israel E, Levy BD. Lipoxin A4 regulates Natural Killer cell and Type 2 innate lymphoid cell activation in asthma. Sci Translat Med. 2013;5:174ra126.

46. Kawai T, Akira S. The roles of TLRs, RLRs and NLRs in pathogen recognition. Int Immunol. 2009;21:317-37.

47. Fili L, Ferri S, Guarna F, Sampognaro S, Manuelli C, Liotta F, Cosmi L, Matucci A, Vultaggio A, Annunziato F, et al. Redirection of allergen-specific TH2 responses by a modified adenine through toll-like receptor 7 interaction and IL-12/IFN release. J Allergy Clin Immunol. 2006;118:511-17.

48. Empey D, Laitinen L, Jacobs L, Gold W, Nadel J. Mechanisms of bronchial hyperreactivity in normal subjects after upper respiratory tract infection. Am Rev Respir Dis. 1976;113:131-39.

\section{Publisher's Note}

Springer Nature remains neutral with regard to jurisdictional claims in published maps and institutional affiliations.

Ready to submit your research? Choose BMC and benefit from:

- fast, convenient online submission

- thorough peer review by experienced researchers in your field

- rapid publication on acceptance

- support for research data, including large and complex data types

- gold Open Access which fosters wider collaboration and increased citations

- maximum visibility for your research: over $100 \mathrm{M}$ website views per year

At $\mathrm{BMC}$, research is always in progress.

Learn more biomedcentral.com/submission 